\title{
The Effect of Self-Regulated Strategy Development on Persuasive Writing: A Quasi-Experimental Study Among Grade 6 Students in Lebanese Private Schools
}

\author{
Najla Mazeh ${ }^{1,2^{*}} \quad$ Nehme Safa ${ }^{2}$ \\ 1.Department of Public Health, Lebanese University, Beirut, Lebanon \\ 2.Department of Educational Sciences, Saint-Joseph University, Beirut, Lebanon
}

\begin{abstract}
Writing plays a critical role in academic, social, and professional domains. Despite this importance students across the globe are facing writing challenges. This outcome required advancing evidence-based instruction, such as the self-regulated strategy development model (SRSD), to enhance students' writing performance. Accordingly, this quasi-experimental study with a pre-test and post-test design examined the effect of the SRSD strategies (POW \& TREE) on elements of persuasive essay, linking words, length of essay, and writing quality of Grade 6 students ( $n$ $=161)$ in three Lebanese private schools where English is taught as a second language. Results showed that the experimental group significantly outperformed the control group on elements of persuasive essay, linking words, length of essay, and writing quality. Results demonstrated that the SRSD writing model was effective in promoting second language persuasive writing of Grade 6 students in three Lebanese private schools. Teachers applied the intervention with fidelity and participants rated the intervention favorably. Limitations and future research directions were also discussed.
\end{abstract}

Keywords: Self-regulated strategy development (SRSD), second language writing, persuasive writing

DOI: $10.7176 / \mathrm{JEP} / 11-32-03$

Publication date: November $30^{\text {th }} 2020$

\section{Introduction}

Writing proficiency is central across educational, communication, social, and career levels. Further, the importance of writing is recognized by the worldwide educational reform attempts to advance effective teaching practices, access the diverse needs of all learners in classrooms, and prevent school failure. Despite the educational attention given to enhance writing achievement across grades, students' are not meeting the expected competencies according to writing standards (Fidalgo et al., 2017). Lacking the competence to plan, generate ideas, set goals, and organize content have been considered as major challenges to students (Harris et al., 2009) because it could be detrimental for the learning process among children, and might limit further educational and employment opportunities for adults (Graham et al., 2015; Harris et al., 2015). This constituted a globally growing concern among different countries including the United Stated, United Kingdom, Europe (Fidalgo et al., 2017) and the Middle East (Esseili, 2019).

Universally, research findings have indicated that practices intended to teach writing are inadequate (Graham, 2019). Within such situation, immense efforts should be directed toward providing schools with effective evidence-based writing instruction that is capable of promoting skilled writers who are knowledgeable, selfregulated, and motivated (Graham \& Harris, 2019). Research conducted in the United States revealed that the majority of students are not developing proficient writing skills. It is reported that $50 \%$ of high school were not ready for writing requirements at university level (Graham \& Perin, 2007a). Similarly, in the United Kingdom, Andrews et al. (2009) indicated low proficiency in writing especially in argumentative writing among students at stage two. Andrews et al. (2009) emphasized the importance of integrating critical thinking and cognitive reasoning in writing instruction to promote skilled writing.

In Lebanon, a multilingual and multicultural country in the Middle East, existing writing practices have been found ineffective in building students' writing competencies and hence impeding academic success (Esseili, 2019). A disparity is prevailing between the aspired principles of the Lebanese English curriculum and the reform plans in enhancing language skills, including writing, resulting in overall unsatisfactory writing performance among students (Esseili, 2019; Shabban, 2013). Studies conducted in Lebanon revealed that the pedagogical and learning approaches and strategies stated in the English Language curriculum were neglected; as a result, many students across all grade levels are falling below expected levels in writing achievement (Awada \& Diab, 2016). Teachers reported that students' lack of skilled writing could be attributed to students' weak writing levels; limited time devoted to teach writing strategies and the process of writing at schools; and lack of use of effective writing strategies (Esseili, 2014).Unfortunately, students' lack of writing proficiency might limit their progress and success not only in schools and universities, but at the professional level as well (Harris et al., 2019; Graham, 2019). Therefore, there is a need to identify effective writing instruction including self-regulated based instruction to ensure proficient English writing performance among Lebanese learners. 


\section{Review of Literature}

Effective instruction aim to fulfill the writing standards and competencies that focuses on building skills related to spelling, handwriting, typing, sentence construction, grammar, in addition to emphasizing the planning and revising strategies of the writing process. Students are required to learn different types of text such as the narrative, informative, and persuasive writing (Festas et al., 2015; Graham, McKeown et al., 2012). The core curriculum for English writing gives importance to building proficiency in persuasive or argumentative writing across all grades. The purpose of this genre is to defend one's position and convince others to agree with the position stated. It requires students in upper elementary grades to use facts, give logical explanations, provide supportive information to persuade the reader, and end the coherently written persuasive essay with a comprehensive conclusion. This process of using persuasive strategies, thinking logically and critically is emphasized in language standards with an aim to extend these skills beyond school context to meet the authentic future career and educational demands in the 21 st century (Harris et al., 2019).

In the same way, these competencies were adopted in the new English Language Curriculum in Lebanon after the education reform conducted in 1997 and 2011; however, the effective application of the curriculum and students' outcomes were questioned (Awada \& Diab, 2016). It is worth mentioning that students learning English as a second language acquire writing skills in similar ways as the native learners (Cumming, 2016). This notion enhances the extent of generalizing research findings in writing from around the world and promotes better understanding and conceptualization of learning and teaching practices in writing.

The different theoretical approaches and writing models have conceptualized writing as a recursive complex process rather than a linear process; thus, setting the stage to a paradigm shift from a focus on product in writing to a focus on process (Harris et al., 2009). These perspectives have emphasized the cognitive, metacognitive, social, and motivational components of writing; consequently, confirming Hayes (1996) view that the cognitive demands of writing draw on students', skills, self-regulation, and strategies. Skilled writing requires recursive process of planning, generating ideas, organizing the ideas, revising, and editing the writing product as proposed by Hayes and Flower's model (1980). Effective teaching practices enable students to use self-regulated strategies in order to regulate the planning, organization, and composing process during writing. In addition, promoting students awareness, control, and knowledge about writing strategies and processes have been essential to cognitive and self-regulation based models including those of Hayes (2006) and Zimmerman and Reisemberg (1997).

Cognitively, Hayes and Flower's model (1980) considered writing as a problem-solving, goal-oriented process that requires proficient writers to employ strategies (e.g. think aloud, planning), regulate, monitor, and control the writing process in a recursive manner. Additionally, Zimmerman and Risemberg (1997) proposed a model that focused on the role of self-regulation in writing. According to this model, writing involves the interaction of strategies to control one's actions, the writing environment, and the internal thoughts and processes.

The overall theories and models emphasize the importance of planning, revising, and self-regulation in promoting writing skills. These essential elements and components constituted the base for different writing models including the strategy-based intervention. Strategy-based interventions as cognitive models are considered as the most effective methods for improving writing performance and self-regulated independent learners (Robledo-Ramón \& García, 2017). Strategy-based instruction involves teaching knowledge of strategies and concepts. Further, self-regulation and metacognitive knowledge are essential in strategy instruction to support students' autonomy in using knowledge and skills flexibly (MacArthur, 2017). The different aspects of selfregulation articulated in strategy instruction are informed by the social cognitive theory of Bandura (1986), Zimmerman and Risemberg (1997), and the sociocultural theory of Vygotsky (1986). One of the most effective strategy-based cognitive models is the SRSD writing model.

As illustrated, drawing on the different perspectives, a comprehensive understanding of writing development and writing instruction necessitates research integration across social, cognitive, and motivational concepts (MacArthur \& Graham, 2016). This declaration is at the heart of the SRSD model which also has attended to evidence-based practices that have informed teaching and learning in writing for different grade levels and contexts. A variety of primary evidence-based instructional practices designed to teach writing include: providing supportive learning environment, promoting goal-setting and planning, interactive collaboration, and enhancing students' writing strategies and skills. These practices are manifested in the self-regulated learning which is described as an active, constructive process that allows learners to set goals for their learning and then attempt to monitor, regulate, and control their cognition, motivation, and behavior (Wolters et al., 2003). To manage the challenges of writing, skilled writers rely on various self-regulation strategies which include: (a) planning, (b) setting goals, (c) organizing content (d) self-monitoring, (e) revising, (f) managing the environment, and (g) self-reinforcing (Harris et al., 2011). All these dimensions should be brought together when designing instruction to promote skilled, knowledgeable, and self-regulated. In this regard, lack of effective instruction is detrimental to writing proficiency. For this reason, using effective writing instruction is required to promote skilled writing (Graham, McKeown et al., 2012; Bruning \& Kaufman 2016).

As discussed in existing research, effective instructional practices are employed to promote writing quality 
and improve writing achievement. The SRSD model is characterized by enhancing students' awareness to effort, enabling students to regulate the use of strategies, the process of writing, and their behavior during writing in an active collaborative context. In addition, multiple self-regulation strategies are embedded in the SRSD model such as planning, organizing, goal-setting, self-instruction, self-monitoring, and self-reinforcement. SRSD has been powerful in promoting writing achievement among students with diverse needs (De la Paz \& Graham, 2002).

SRSD involves six essential stages of instruction that aim to develop writing and self-regulation strategies. It has been informed by multiple theories such as the motivational, behavioral, cognitive, social cognitive, sociocultural, and socio-cognitive perspectives. It is worth mentioning that four theoretical approaches are at the core of the SRSD model including the cognitive-behavioral model of Meichenbaum (1977), the social cultural theory of Vygotsky's (1978), strategic instruction model of Deshler and the sequence or steps of strategy attainment by older learner, the metacognitive development proposed by Brown and colleagues (1981), and others. This integration and triangulation of multiple theories has given the SRSD model its uniqueness and attributed to its effectiveness (Murphy et al, 2017). It is a theoretically integrative approach, rather than an approach based on single theory. The elements and characteristics of SRSD (e.g., scaffolded explicit instruction and criterion-based learning) have been based on various theories and paradigms, rather than a sole theory. It is assumed that a single theoretical perspective of writing, learning pedagogy, and teaching cannot comprehensively address the complex nature of learning to write in varied contexts and among diverse students (Harris, 2018; Harris \& Graham, 2017). Adopting theoretical pragmatism, the SRSD model asserts that addressing the complex needs of learning and writing require the integration of multiple theories rather than relying on one single theory (Harris \& Graham, 2017). This contributes to the effectiveness of SRSD in addressing the complex demands of writing and responding to students' writing challenges experienced worldwide. The theoretical integration of SRSD makes it a powerful and robust writing model (Harris \& Graham, 2017).

Previous research studies on the SRSD writing model highlighted the effectiveness of this model in light of significant improvements in students' writing performance and self-regulated learning at different grade levels and among diverse learners (Barkel, 2018). Further, De la Paz and Sherman (2013) claimed in a study that novice writers lack several important skills in writing including limited focus on planning before writing, and show ineffective attending to meaning intended in their writing. This problem guided De la Paz and Sherman (2013) to conduct a multiple-probe design study to examine the effect of the SRSD intervention on revising expository writing strategy among Grade 6 English learners and non-English learners with varied writing levels. Results indicated that students showed improved revision skills and better writing quality. The results provide evidence on the effectiveness of the SRSD model in promoting writing performance and writing knowledge of English learners and non-English learners in general classroom contexts.

A different study by Cuenca-Carlino et al. (2018) used an experimental single-case design to investigate the effect of the SRSD strategies (POW and TREE) on opinion writing among English language learners (ELLs) in primary grades with and without learning problems. Findings demonstrated improved opinion writing performance and knowledge for all students in terms of number of elements written in the essay, quality of the essay, and length of opinion essay written after intervention.

In Portugal, Festas et al. (2015) investigated the effect of SRSD instruction on opinion writing essay of Grade 8 students. Results indicated that students who received SRSD instruction revealed better performance on elements and length of opinion essay in comparison to the control group who received the traditional writing program. As for social validity measures, both teachers and students who participated in the study considered the intervention to be significant. Measures of social validity and treatment fidelity are important for supporting the availability of implementing the SRSD model as an evidence-based practice in other contexts other than the United States. Another study in Portugal by Limpo and Alves (2013) examined in a quasi-experimental design, the effectiveness of the SRSD writing model to promote fifth and sixth graders' opinion essay writing. Findings from this study demonstrated that the SRSD writing model is effective in promoting students' skills to construct sentences, plan and revise their writing which resulted in better and longer opinion essays. Limpo and Alves's (2013) study emphasized the role of self-regulation and planning in promoting the overall writing quality in opinion essay. Thus, these components were basic in the SRSD model applied in the current study, which addressed the effect of the SRSD model on more opinion writing aspects (e.g., elements of persuasive essay and linking words).

In Lebanon, studies that examined the effect of the SRSD writing model on writing achievement were not found up to the knowledge of the researcher. Accordingly, the reviewed studies conducted in the Lebanese context targeted self-regulated learning among high school or university students (Daouk, 2009; Itani, 1996) or used correlational methods to determine the relation between self-regulation and achievement (Itani, 1996; Rubeiz, 1995). Unfortunately, despite the national and international calls for promoting effective instructional writing programs at different grade levels, research in Lebanon has not sufficiently addressed the impact of the SRSD instruction on writing performance. Studies applying SRSD using the experimental design have not been conducted in the Lebanese context. Accordingly, there is a need to attend to the complexity of writing by using the SRSD model as an evidence-based self-regulated model to ensure enhancing students' persuasive writing skills. 
Thus, this current study intended to examine in the effect of using self-regulated strategy development (SRSD) on English language writing achievement of Lebanese students in the second cycle.

Collectively, the studies reviewed in this section highlight the need to promote proficient writing skills among learners worldwide (Graham, 2019) and provide stronger evidence on the effectiveness of self-regulated strategy development (SRSD), as an instructional model to improve writing performance and self-regulation of native (L1) and nonnative speakers (L2) of English (e.g., Barkel, 2018). The research studies maintained that there is a need to teach first and second language learners the essential metacognitive strategies such as goal-setting, planning, organizing, and self-monitoring to promote skilled writing. However, internationally and nationally writing competency among different grade levels is considered to be unsatisfactory (Graham, 2019; Harris, Esseili, 2019). This gave more support for applying the SRSD model in the Lebanese context where English is taught as a foreign or second language. Results from a large body of research provided significant evidence that SRSD is effective for promoting writing skills (Fidalgo \&Torrance, 2017). SRSD has enhanced the development of writing strategies for different genres including expository, narrative, persuasive, report writing, and standardized writing tests. SRSD has succeeded in improving students' writing skills (Harris \& Graham, 2009).

Despite the continuous attempt to improve practices to teach writing and promote writing performance, there are gaps in research knowledge in these areas. Intervention studies focusing on English as a second language are still limited (Graham \& Harris, 2017). The use of experimental design is considered an effective method in determining the impact of intervention and is trusted as an approach to identify effective teaching practices in writing (Graham \& Harris, 2017). Examining the effect of the SRSD writing model as a self-regulated strategybased instruction in the Lebanese context promotes understanding of writing practices which could be important to the growth of research in writing instruction, not only on the local level but also on the global level in an attempt to promote universal writing practices. Unfortunately, the SRSD writing model has not been examined in the Lebanese context up to the knowledge of the authors. Hence, the current study intended to examine the effectiveness of the SRSD writing instruction guided and supported by research results in order to respond to the writing challenges of Lebanese learners in cycle two in private schools.

To conclude, drawing on the concepts that are delineated in the different theoretical approaches and comprehensively embedded in the SRSD model, in addition to extensive research evidence on the SRSD model from which the research questions and hypotheses of the current study emerged, the current study aims at examining the effectiveness of the SRSD model writing intervention on persuasive writing of Grade 6 students learning English as a second language. Findings from this study would help fill a gap in literature by promoting understanding the SRSD writing model's effect on improving writing achievement in the Lebanese context. The quasi-experimental design used in the current study aimed to examine the theoretically based and derived hypotheses of the current study involving the effect of self-regulated strategy-based instruction on persuasive writing performance in grade 6.

The current study involved examining the following hypotheses which were derived from the previous relevant research findings presented above. Accordingly, the study predicted that Grade 6 students would score higher on persuasive essay, in terms of elements of persuasive elements, linking words, writing quality, and number of words, after receiving the SRSD instruction in comparison to Grade 6 students who would receive the traditional writing instructions. The present study predicted that both teachers and students in the experimental group would positively rate the SRSD intervention as an effective and useful writing model.

\section{Purpose of Study}

Building on a larger mixed methods quasi-experimental study, the primary purpose of the present study was to investigate the effect of SRSD, as a writing instructional model on opinion writing performance of Grade 6 students in three Lebanese private schools. Thus, the current study addressed the following questions:

1- What is the impact of the SRSD strategies (POW and TREE) on Grade 6 students' persuasive writing performance in relation to elements of persuasive writing, linking words, essay length, and writing quality?

2- To what extent would students and teachers in the experimental group rate the SRSD intervention as being effective in improving students' writing performance?

\section{Methodology}

The present study extended research on the SRSD writing model through designing an intervention to examine the effect of this model in enhancing the writing performance of students in Lebanon. Accordingly, a quasiexperimental design was used to investigate the effect of the SRSD writing model as a self-regulated writing model (independent variable) on the persuasive writing performance (dependent variable) of Grade 6 students in three Lebanese private schools.

\subsection{The Setting and Participants}

The study involved students in Grade 6 in three purposefully selected private schools in Mount Lebanon. All 
principals expressed willingness and offered consent to participate in the study. Six female teachers participated in the study. All earned university degrees in teaching English in elementary education. Further, a total of 161 students from three Grade 6 intact classes were invited to participate in the study. Parents' consent and student's assent were obtained for all students (100\% of the students in the classrooms). All participating students whose spoken language is Arabic were homogenous in relation to culture, nationality, and socio-economic status as all of them were Lebanese and they belong to the middle socio-economic class.

\subsection{Sampling}

This study was conducted in three purposefully selected private schools (School A, B, and C) in Mount Lebanon where English is taught as a second language. Schools were chosen to participate in the study according to the following specific criteria: (a) were private, (b) served students of middle socio-economic status, (c) taught English as a second language, instructed both genders in same classroom, (d) had a minimum of two sections of Grade 6, and (e) used foreign programs and text books with focus on process writing as a method for teaching writing. Two intact classrooms of Grade 6 in each school were randomly assigned to either the experimental or the control groups.

\subsection{Measures}

Several measures were obtained for each persuasive essay including persuasive essay elements, overall writing quality, use of linking words, and number of words or length of essay.

\subsubsection{Total Number of Persuasive Essay Elements}

Persuasive essay parts measure has been validated as an efficient measure in pervious study conducted by Harris et al. (2006). Total number of persuasive essay elements was scored for each essay. Each essay was divided into a minimum of eight functional elements (a premise, three or more reasons, elaborations, and a conclusion) (Graham et al., 2005). A score of 1 was given for each element written. The researcher and another trained rater, blind to condition, scored all essays. At pre-test and post-test, inter-rater reliability using ICC for $100 \%$ of essays for number of persuasive essay elements was $(.97, .98)$ respectively.

5.3.2 Overall Writing Quality

A holistic scoring rubric was used to score the quality of persuasive essays for each participant at pre-test and posttest. Quality was scored on a 1-8 point scale with 1 representing the lowest quality and 8 representing the highest quality. Four anchor points, which represented sample responses with scores of 2, 4, 6, and 8, were used to guide scoring quality of essays. The raters assessed each essay attentively, however not laboriously to form a general impression of overall quality and rate the essay. At pre-test and post-test, inter-rater reliability using ICC for $100 \%$ of essays for writing quality was $(.92, .95)$ respectively.

\subsubsection{Use of Linking Words}

The students in the experimental groups practiced the use of linking or transition words (e.g., first, then, so, therefore...), and were taught that linking words can combine ideas together and help order the reasons clearly. The number of linking words was counted and recorded by the two raters. At pre-test and post-test, inter-rater reliability using ICC for $100 \%$ of essays for linking words was $.97, .99)$, respectively.

5.3.4 Number of Words

Number of Words was defined as total number of words written in the student's persuasive essay. Microsoft word function was used to count words in each essay.

\subsubsection{Student's Social Validity Scale}

The experimental group responded at post-test to a five-item adapted social validity rating scale from Limpo and Alves's (2013) study to measure descriptively the overall level of satisfaction with the SRSD persuasive writing strategies. Students rated their level of agreement on a five-point Likert-type scale $(1=$ strongly disagree; $5=$ strongly agree) in response to the following items: (1) POW + TREE helped me to write better persuasive compositions; (2) POW + TREE helped me to write better in general; (3) I will continue to use the POW + TREE; (4) POW + TREE should be taught to other students; (5) I would like to learn strategies for other types /genres. The score on social validity rating scale was the mean score of the five items.

5.3.6 Teacher's Social Validity Scale

Social validity for teachers, who instructed the experimental group, was used to assess the acceptability of the intervention. The Intervention Rating Profile (IRP-15 rating scale; Witt \& Elliott, 1985) used in the study was adopted and adapted from a study by Harris and her colleagues (Harris et al., 2012). The internal consistency of the scale ranged from .88 to .98 . Responses were obtained via a 5 -points Likert scale $(1=$ strongly disagree; $5=$ strongly agree) in response to the following 9 items: (1) SRSD is an acceptable writing model for students in my class; (2) SRSD will prove effective in improving student's writing (3) I would suggest the use of this SRSD writing model to other teachers; (4) Most teachers would find SRSD writing model suitable for students of different writing levels; (5) I would be willing to use this writing strategy in most classroom settings; (6) Use of SRSD writing model will produce no negative consequences for the student; (7)The procedures used in SRSD writing 
model for persuasive essay are well organized and clear; (8) SRSD writing model is a good way to handle the students' writing needs; (9) Overall, SRSD writing model is beneficial for the class. The score for social validity rating scale was the average score of the nine items.

5.3.6 Treatment Fidelity

Several measures were taken to ensure that teachers in the experimental groups implemented the SRSD lessons with fidelity as intended. Each teacher participated in training for 3-4 days (2 hours per day) prior to the intervention and received lesson plans and instructional materials. The researcher attended 100\% of the sessions in each section and used a checklist to make sure that steps are implemented as required. Steps of the lessons across all the three experimental sections were completed with $100 \%$ of accuracy, hence, a very high degree of fidelity.

\subsection{Data Collection Procedures}

Teachers in the experimental group received training (6-8 hours) to ensure proper implementation of the SRSD model. The training plan was adapted from an online training material offered to the researcher by founder of SRSD Karen Harris

Students in the experimental and control groups completed a pre-test one week before the SRSD intervention and a post-test directly after the end of the intervention. Essay prompt were given to both sections on the same day following similar procedures. Students and teachers in the experimental group completed a rating scale after the intervention to assess the social validity of the SRSD model.

As for the intervention, English language teachers delivered writing instruction for the experimental groups. Students were taught POW and TREE strategies for persuasive essays. Instruction for approximately 15-18 lessons were given for 50 minutes two times a week for 8-10 weeks. The SRSD instruction was given in six recursive stages: (1) Develop Background Knowledge, (2) Discuss it, (3) Model it, (4) Memorize it, (5) support it, and (6) independent performance. The control groups received the regular writing instruction from their regular English language teachers.

\subsection{Data Analysis Procedures}

Descriptive and inferential statistics included reporting and comparing the pre-test and post-test mean scores and ANCOVA of the experimental and control groups on the persuasive writing measures. The independent-samples $t$-tests were used to measure the difference between the mean scores of the experimental and control groups at the pre-test and post-test level on the persuasive writing measures. The effect size was calculated for the independentsamples $t$-test. Descriptive statistics of the social validity rating scales were obtained for the experimental group.

\section{Results}

Results were obtained from participants' scores on persuasive essays at pre-test and post-test to answer the first research question of the study about the effect of the SRSD intervention on persuasive writing measures. In addition, results of students' and teachers' social validity scales at post-test were analyzed.

Based on preliminary data analysis, pre-test results revealed that there were no pre-existing differences between the mean scores of the experimental and control group in respect to the dependent variables (persuasive elements, linking words, and writing quality) of the study, thus, independent-samples $t$-test was used to determine group performance at post-test. Analysis of covariance (ANCOVA) was analyzed for number of words because significant differences on pre-test mean scores existed between the two groups on this variable.

The first question examined the effect of the SRSD writing intervention on the English persuasive writing performance of Grade 6 students. Results of independent-samples $t$-test (see Table 6.1) and ANCOVA (see Table $6.2,6.3$ ) were obtained for the different writing measures as follows.

\subsection{Group Differences on Elements of Persuasive Essay}

An independent-samples $t$-test was conducted to compare the mean scores of persuasive elements written in an essay at post-test between the experimental and control groups. Levene's test value $(p=.000<.05)$ indicated unequal variances for the groups. Results showed that there was a significant difference in post-test scores between the two groups $\mathrm{t}(115.53)=14.04, p=.000<.05$. It was evident that the experimental group $(M=9.48, S D=2.97)$ scored significantly higher than the control group $(M=4.04, S D=1.68)$. The magnitude of the difference in the means (mean difference $=5.43,95 \%$ confidence interval $C I$ [4.67 to 6.20]) was remarkably large $(d=2.25$ ) according to Cohen's (1988) guidelines. Thus, this result provided evidence that SRSD improves students' performance in relation to inclusion of essential elements required in persuasive essay, and as such the one tailed hypothesis for this question was supported.

\subsection{Group Differences on Use of Linking or Transition Words}

Results of the Levene's test $(p=.216>.05)$ indicated that equal variances for the groups was met. The findings from independent-samples $t$-test at post-test yielded significant difference in scores on linking words between the 
experimental and control group, $t(159)=7.35, p=.000<.05$ one-tailed. The experimental group showed significantly higher mean scores on use of linking words $(M=6.18, S D=2.12)$ in comparison to control groups $(M=3.61, S D=2.29)$. Additionally, the magnitude of the effect size in the mean difference (mean difference $=$ $2.57,95 \% C I$ [ 1.88 to 3.26$]$ was considered to be very large $(d=1.13)$ based on Cohen's (1988) guidelines. Thus, results supported the hypothesis which predicted that experimental group would show better performance in using transition or linking words in their essays after receiving the SRSD intervention in comparison to the control group.

\subsection{Group Differences on Quality of Persuasive Essay}

An independent-samples $t$-test was conducted to compare the scores of groups on overall quality of persuasive essay. The significance for the Levene's test was $p=.776>.05$ indicating that equal variances were assumed. Results of independent-samples $t$-test showed a statistically significant difference between the scores of writing quality of the experimental group and the control group, $t(159)=9.93, p=.000<.05$, thus, supporting the one tailed hypothesis which predicted that the SRSD intervention would improve students' quality of persuasive writing in comparison to the traditional writing program. Findings revealed that scores on quality of essays of the experimental group at post-test $(M=4.88, S D=1.05)$ were significantly higher than that of the control group $(M$ $=3.23, S D=1.04$ ). The magnitude of the difference in the means (mean difference $=1.64, C I[1.31$ to 1.9$]$ was very large with an effect size for this difference $(d=1.57)$ exceeding Cohen's (1988) values for a large effect, indicating that the obtained difference between the two groups was attributed to the SRSD intervention.

Table 6. 1 Independent-Samples t-Tests of the Writing Measures at the Post-tests by Group

\begin{tabular}{l} 
Writing measures \\
\cline { 2 - 4 }
\end{tabular}

\subsection{Number of Words}

A one-way between-groups analysis of covariance (ANCOVA) was applied to determine the effect of the SRSD writing model in increasing number of words written in a persuasive essay. The difference in post-test mean scores was examined on number of words between the experimental group and control group, after controlling for the initial pre-test scores on number of words which were used as the covariate.

Results showed that value of Levene's test was not significant, $F(1,159)=.641, p=.425$, indicating that the assumption of homogeneity of variance was met. Results of ANCOVA indicated significant difference on mean scores of number of words between the two groups at post-test due to the effect of the SRSD intervention, $F$ (1, $158)=21.516, p=.000<.05, \eta p 2=.120$. The value of partial eta squared is close to large effect size according to Cohen's (1988) guidelines, implying that the SRSD intervention was significantly effective in increasing the number of words for the experimental group. The adjusted means indicated that the score on number of words was higher in the experimental group $(M=109.9)$ in comparison to the control group who showed a decline in number of words from pre-test to post-test $(M=83.3)$. This result along with $F(1,158)=21.516, p=.000<.05, \eta p 2$ $=.120$ supported the hypothesis stated in the study which assumed that the SRSD intervention would increase the number of words written in a persuasive essay in the experimental group in comparison to traditional writing program delivered to the control group.

Further, the results showed that the covariate was also significant, $F(1,158)=95.039, p=.000<.05$, partial eta squared $\eta p 2=.376$; hence, it was statistically adjusted for its effect so that the relationship between the treatment and the outcomes is assessed properly (Creswell, 2012). The pre-test mean score on number of words as a covariate was significant and explained $37 \%$ of the variance in this measure. ANCOVA results are presented in 
Tables 6.2 and 6.3

Table 6.2 Analysis of Covariance of Post-test Number of Words Mean Scores at as a Function of Instruction, with Pre-test Number of Words Scores as Covariate

\begin{tabular}{|c|c|c|c|c|c|c|}
\hline Source & $d f$ & $S S$ & $M S$ & $F$ & $P$ & $\eta_{\mathrm{p}}^{2}$ \\
\hline $\begin{array}{l}\text { Pre-test number of words } \\
\text { (covariate) }\end{array}$ & 1 & 122339.224 & 122339.224 & 95.039 & .000 & 376 \\
\hline Group & 1 & 27696.500 & 27696.500 & 21.516 & .000 & .120 \\
\hline Error & 158 & 203385.073 & 203385.073 & & & \\
\hline Total & 161 & 1816296.000 & & & & \\
\hline
\end{tabular}

Note. $d f=$ degrees of freedom, $S S=$ standard score, $M S=$ mean square,$F=$ test statistic, significance level $p<.05$, $\eta_{\mathrm{p}}{ }^{2}=$ partial eta squared indicates effect size and is compared to Cohen's (1988) guidelines $(.01=$ small effect, .06 $=$ moderate effect, $.14=$ large effect).

\begin{tabular}{|c|c|c|c|c|}
\hline \multirow[b]{2}{*}{ Section } & \multicolumn{2}{|c|}{ Unadjusted mean scores } & \multicolumn{2}{|c|}{ Adjusted mean scores } \\
\hline & $M$ & $S D$ & $M$ & $S E$ \\
\hline Exp. group $(n=76)$ & 104.75 & 42.41 & 109.93 & 4.15 \\
\hline Cont. group $(n=85)$ & 87.89 & 47.66 & 83.25 & 3.92 \\
\hline \multicolumn{5}{|c|}{$\begin{array}{l}\text { Note. } M=\text { mean scores, } S D=\text { standard deviation, } S E=\text { standard error. Exp. = experimental group, Cont. }= \\
\text { control group, } n=\text { number of participants in group. Unadjusted post-test means refer to means before controlling } \\
\text { for the covariate. Adjusted post-test means refer to means after controlling for the covariate. Covariate is pre- } \\
\text { test scores of number of words. }\end{array}$} \\
\hline
\end{tabular}

\subsection{Social Validity}

Results from students' and teachers' rating scales indicated a high level of acceptability of the SRSD intervention. Results obtained from students' social validity ratings $(M=4.3, \mathrm{SD}=0.5)$ revealed that students perceived the SRSD intervention to be effective and considered the SRSD strategies to be helpful to the extent that they improved their writing abilities. Further, students claimed their willingness to sustain using and learning more similar strategies in the future.

All teachers $(n=3)$ in the experimental group rated the nine statements about the effectiveness of the SRSD intervention on a 5-point Likert-type scale. Results showed high validity levels; the three teachers strongly agreed $(M=5, S D=0)$ that the SRSD intervention was highly effective and beneficial for students; they also indicated strong willingness to use the SRSD strategies in the future and recommended teaching such strategies by other teachers.

\section{Discussion}

The present study examined the effect of the SRSD intervention on persuasive writing performance of Grade 6 students learning English as a second language in three private schools in Lebanon. Results support the prediction of the present study which assumed that the SRSD writing model would significantly and effectively promote students' writing performance at post-test, as compared to the control group. Results from the independent-samples $t$-test showed significant increase in the mean scores of the experimental group on persuasive elements, number of words, linking words, and writing quality as compared to the control group.

As indicated by results of Cohen's $d$, the magnitude of the increase, the SRSD intervention was highly significant for all measures, indicating that the self-regulated strategies of the SRSD model are effective in promoting persuasive writing. Additionally, compatible with prediction of the present study, the SRSD intervention was highly effective in yielding a significant increase in post-test mean scores in favor of the experimental group on number of words written in a persuasive essay, after controlling for pre-test mean scores as a covariate. The improved performance on number of words written in persuasive essays after the SRSD intervention gives support to Scardamalia and Bereiter's (1986) cognitive perspective that text generation is a targeted outcome in writing instruction.

Comprehensively, the findings of the current study confirm the effectiveness of the SRSD intervention, as a self-regulated strategy-based writing model, in promoting persuasive writing performance among Grade 6 students learning English as a second language in the Lebanese context. The improved writing performance of students in the experimental group in this study suggests that the strategies used in SRSD intervention, including modeling, scaffolding, interaction, and practice, are essential in promoting proficient writing skills (Hodges, 2017). This is consistent with the sociocultural and socio-cognitive perspectives, which have ascertained that providing proper modeling, adequate practice, supportive feedback, and collaborative interaction during writing tasks improve students' writing performance. 
In general, the above-mentioned results are in line with previous findings of research studies involving second language learners or English learners in elementary classrooms (Barkel, 2018; Cuenca-Carlino et al., 2018; De la Paz \& Sherman, 2013; Festas et al., 2015) in showing the effectiveness of the SRSD intervention in enhancing students' writing performance.

Findings of the writing performance in this present study are generally consistent with results obtained in Barkel's (2018) study. Similar to the significant effect of the SRSD strategies (POW and TREE) obtained in the preset study, results from Barkel's (2018) study revealed improvement in students' writing performance in number of persuasive elements, writing quality, and number of linking words from baseline to post-test. These findings are seen as a result of using the SRSD instruction (POW and TREE strategies) for opinion essay. To illustrate, POW strategy enabled students to plan during the writing process, generate ideas and vocabulary, consider genre elements, and organize their ideas. Furthermore, TREE strategy was used to teach students the elements of persuasive genre, and to provide them with a model on how to write a coherent opinion essay. The SRSD instruction also involved procedures for teaching students how to self-regulate their behavior and the writing process by using goal setting, self-instruction, self-reinforcement and self-monitoring. These evidence-based strategies were effective in improving students' writing performance.

However, Barkel's (2018) findings on essay length are at variance with the significant results obtained in the present study on the same measure. In Barkel's (2018) study, improvement on length of essays was not consistent among all students from baseline to post-test. This outcome was shown in previous studies (e.g., Barkel et al., 2018; Festas et al., 2015). In attempt to explain this finding, Barkel (2018) ascertained that increasing text length was not a goal of the SRSD intervention. To illustrate, in the present study, as in most SRSD studies, the emphasis primarily focused on improving the overall writing quality in students' writing and self-regulated learning. The focus of the SRSD instruction centers on explicitly teaching students how to include structural genre elements, set goals, monitor their performance, and use strategies to achieve the writing goals. Thus, the aim of the SRSD instruction is to enhance completeness rather than increase length of the essay (McKeown et al., 2019).

In addition, the effectiveness of the SRSD writing model in improving writing performance is supported by findings obtained in Cuenca-Carlino et al.'s (2018) study. The SRSD intervention yielded positive effects on opinion writing of English learners with and without disabilities in Grades 2 and 3. Group results showed improvement from pre-test to post-test on all writing measures (elements of an opinion essay, essay quality, and length of words written). These positive results support findings from the current study in respect to all the writing measures. These writing outcomes are attributed to the use of explicit, structured, and scaffolded SRSD instruction embedded in SRSD model, which foster mastery of required skills and strategies as indicated by Brown, Campione, and Day's theoretical perspective (1981).

The findings from the present study on the impact of the SRSD model in promoting students' overall writing quality are aligned with results by De la Paz and Sherman's (2013) study. The former study indicated the effectiveness of the SRSD model in improving the performance of Grade 6 students on writing expository essays in their ESL classes. Specifically, all students showed gains at post-test in the number of meaningful changes in texts written after using SRSD strategies. As a result, students demonstrated improved overall writing quality.

Similarly, the improved essays quality of the experimental group shown in the present study provides additional evidence on the effectiveness of SRSD regulatory strategies in promoting overall quality of opinion essay in a different educational and cultural context. Literature has supported that the SRSD model is impactful in improving writing quality, which reveals growth in students' writing including enhancing their skills to plan, organize, and generate ideas (Graham et al., 2013; McKeown et al., 2019). The research evidence on the effectiveness of SRSD in improving writing quality support Zimmerman and Risemberg's (1997) theoretical stance which proposed that proficient writing is accomplished by the use of different self-regulatory strategies to manage the writing task and one's cognitive behavior which in turn result in promoted quality of writing.

Findings from the current study on the effect of self-regulated strategy development (SRSD) on students' writing outcome specifically elements of persuasive genre are also consistent with previous results obtained in an experimental study by Festas et al. (2015). Festas et al. (2015) examined the impact of the SRSD model on Portuguese students' opinion writing in Grade 8 after provision of practice-based professional development (PBPD) for teachers. Results from Festas et al. (2015) indicated that the experimental group showed improved performance on structural elements of opinion essay (pre-test $M=3.56$, post-test $M=6.07$ ) in comparison to the control group (pre-test $M=3.90$, post-test $M=3.62$ ). Another important purpose of Festas et al. (2015) study was to further support generalizability and effectiveness of the SRSD instruction as an evidence-based instruction in different cultural contexts. Accordingly, to enhance treatment fidelity, teacher training program in Festas et al. (2015) study focused on modeling, practicing, and discussing the SRSD lessons. Similarly, the current study provided PBPD for SRSD to ensure that instruction is delivered effectively as an aspect of treatment fidelity and consequently enhancing the validity of results obtained from the experiment (Graham \& Harris, 2014). Furthermore, to demonstrate the importance of PBPD for SRSD, Finlayson and McCrudden (2020) indicated that the researchers, in most of the studies which focused on writing intervention in whole classroom setting, applied themselves the 
SRSD instruction with participants. Such a practice would limit teachers' ability to independently apply the SRSD writing model with efficacy due to lack of training, which in turn would diminish the sustainability of applying the SRSD writing instruction after the end of the research.

In summary, findings in the present study demonstrated that the experimental group outperformed the control group in using self-regulated writing strategies and as a result revealed enhanced structure and quality of opinion writing performance after receiving the SRSD intervention. Collectively, the improvement would be attributed to the effect of the self-regulated skills which are essential to attain proficient writing. These significant findings lend support to several theoretical perspectives and maintain the assets of the SRSD intervention as a multifaceted theoretically integrated model.

The enhanced writing performance of students who received the SRSD intervention in the present study support the cognitive-behavioral view of Meichenbaum (1977) on the importance of enabling students to monitor and regulate their own behavior in order to achieve intended goals in an interactive learning environments by using dialogue, modeling, and scaffolding as means to develop active self-regulated learners. These strategies are stressed in the socio-cognitive theory of Vygotsky (1978), which also highlighted the effect of self-regulation and self-control in promoting independent learning. Further, the results in the present study give evidence on the effective role of self-regulation, strategy instruction, and self-control in promoting writing performance as proposed by Brown, Campione and Day (1981). These aspects are targeted in an explicit and structured manner in SRSD model to ensure proficient writing performance.

Specifically, students' awareness during writing to the skills used and knowledge attained in addition to the ability to know how, when, and why to use these skills give support to Zimmerman and Risemberg's (1997) claim that students are self-regulated writers who are capable of monitoring and controlling their behavior and writing environment to attain the writing goals effectively. The emphasis on goal-oriented and self-regulation aspects of writing in the SRSD model to enhance writing skills also confirms Hayes and Flower's (1981) cognitive view of writing as a complex, metacognitive, and recursive process. According to Hayes and Flower's (1981) cognitive view, Hayes's (1996) notion and Graham's (2018) claim, to achieve writing proficiency students should rely on self-regulation and receive explicit instruction on how to effectively and recursively use writing and self-regulatory strategies such as planning, goal-setting, revising, monitoring, and self-instruction. Additionally, the improved writing performance of students in the experimental group in this study suggests that the strategies used in SRSD intervention, including modeling, scaffolding, interaction, and practice, are essential in promoting proficient writing skills (Hodges, 2017). This is consistent with the sociocultural and socio-cognitive perspectives, which have ascertained that providing proper modeling, adequate practice, supportive feedback, and collaborative interaction during writing tasks improve students' writing performance.

In sum, the present study provides further evidence on the significant effect of SRSD in promoting persuasive writing skills in classrooms where English is taught as a second language. Furthermore, the social validity results obtained in response to the second question confirm the prediction of the current study that both students and teachers in the experimental sections would positively perceive the SRSD intervention to be useful and effective.

Social validity scores of both students and teachers were highly positive. Both students and teachers found the SRSD intervention to be socially significant with practical strategies that yielded effective writing outcomes. They considered the SRSD strategies to be very effective, showed willingness to continue using such SRSD strategies in the future, and recommended teaching these strategies to other students. High levels of social validity toward the SRSD intervention provide extra evidence for replication and scaling up to further studies. The significant students' social validity results in the present study are consistent with results obtained in Limpo and Alves's (2013). Similarly, high positive teachers' social validity results in the present study support previous results of Festas et al. (2015) which reported high positive teachers' perception regarding SRSD treatment.

In addition to assessing the social validity of the experiment, the current study also examined treatment fidelity to indicate the extent to which the SRSD treatment was conducted as intended. Finlayson and McCrudden (2020) highlighted the importance of including teachers' data (e.g., treatment fidelity and social validity) in providing significant data about the implementation of instructional interventions and students' performance, the effectiveness of the intervention, and participants' willingness to use the strategies in the future. Hence, this implies that the intervention is sustainable. Achieving high treatment fidelity levels reflect more trust in results obtained due to the efficacy in applying the treatment (Smith et al., 2007). Notably, assessing treatment fidelity in research studies is still limited despite its importance in educational research and specifically in experimental design as it increases research validity, facilitates replication, and advances educational practices according to Smith et al. (2007). Accordingly, the present study fills this gap by meeting the requirements of social validity as mentioned previously in addition to ensuring requirements of treatment fidelity.

\section{Conclusion, Implications and Recommendations for Future Studies}

Overall, the present study contributes to the solid body of evidence on SRSD effectiveness; the SRSD instruction was effective in promoting proficient persuasive writing of Grade 6 students in intact classrooms in Lebanese 
private schools. Additionally, meaningful insights from the present study reveals that sufficient attention to writing instruction is still lacking in the Lebanese context despite the importance of writing in learning and the emphasis on learning writing skills in the Lebanese curriculum.

Attaining proficient writing competencies that involve higher order thinking in writing, use of writing for different purposes is closely tied to the value given to writing from teachers and students, which in turn shapes how writing is taught. The current writing instruction is still focusing mainly on mechanics of writing and giving little emphasis and time to explicit teaching of planning and organization strategies. It is apparent that if teachers view writing as highly important and understand how writing develops, they will put more effort to develop students' writing by using and developing high quality writing programs. Similarly, if students perceive writing as essential for their success at school, and are aware of writing process, they will be motivated to achieve the writing goals willingly. Accordingly, writing as a tool for learning and communication occurs within a writing community where teachers as well as students share roles, responsibilities, and values, and simultaneously use several types of resources and draws on their background to achieve the writing goals (Graham, 2019). Undoubtedly, this context requires effective writing instruction that supports learners meaningfully; use writing for real purposes; develop process, skills, and writing knowledge, in addition to linking writing to reading and other subject areas. Apparently, shifting teachers' and students' value toward writing, emphasizing formative assessment, and enhancing teaching practices that target purpose of writing, writing skills, knowledge, selfregulation, and motivation are critically demanded worldwide (Esseili, 2019; Graham, 2019). This objective was at the core of the current study.

In light of the above-mentioned study results and insights, a set of potential educational implications that can promote students' writing proficiency and self-regulated learning is proposed.

To begin with, results of this present study and previous studies provide empirical evidence on the validity and reliability of the SRSD instructional model in both L1 and L2. It is recommended to include explicit strategy instruction in any writing curriculum because it is proven to be one of the most effective writing methods in improving writing performance. Teachers can benefit from the flexible and adjustable framework of the SRSD model to accommodate the writing strategies in accordance with curriculum requirements and students' individual needs.

Generally, results also acknowledge the role of the SRSD model in fostering the development of selfregulated learners who are independent, capable, persistent, confident, goal-oriented, and perceiving of writing as a lifelong learning tool. The outcome calls for effective integration of self-regulated strategies included in the SRSD model within L2 writing instruction to attain skilled writing. Findings from this study also suggest that teaching writing is a demanding task that necessitates committing more time to teach writing in classroom to provide students with sufficient practice opportunities necessary to master critical writing processes such as planning, organizing, setting goals, monitoring performance, and collaborating with others to accomplish the writing task. Empowering students to use these processes will promote their composing skills in English and in other academic areas especially those which require writing like science and social studies, thus, ensure their current and future success. Remarkably, Fidalgo et al. (2017) highlighted that strategy-based instruction (e.g., SRSD model) is considered among the most effective teaching instruction for promoting writing performance, in addition to learning other content domains including literature, science, social studies, history and so on.

In this regard, advancing evidence-based practices involves preparing teachers to adopt these practices through well-structured high quality training programs that help teachers become more competent, confident in their abilities, and motivated to apply such practices. Hence, to achieve this outcome, educational policy-makers and school personnel in Lebanon should focus on the importance and value of writing across domains; consequently, propose a new vision to change how writing is taught based on the best practices. Additionally, universities, who offer literacy programs, can also play an important role in preparing teachers to provide effective writing instruction by offering writing courses that focus on evidence-based methods and strategies for teaching writing with field experience at schools. It is evident that teachers who possess a positive view toward writing have confidence in their skills in teaching writing, and value evidence-based practices that play important role in delivering high quality instructions (Graham, 2019).

\subsection{Recommendations, Limitations, and Directions for Future Research}

As the results from the current study demonstrated that the SRSD model improved the writing performance of grade 6 students in Lebanese private schools, these findings contribute to further research avenues.

Despite the significant results obtained in the present study, due to the effect of the SRSD writing instruction on writing performance, the study involved Grade 6 students in only three Lebanese private schools. Thus, future research might determine potential effectiveness of the SRSD instruction on different genres or grade levels in the Lebanese context in both public and private schools using mixed methods design. Future studies should also examine the relation between self-regulated strategies, self-efficacy, and writing attitude, and determine how these variables relate to writing performance. 
Since the sample in the current study involved Grade 6 students learning English in three private schools in Lebanon, generalization of findings from this study would be limited to similar population with similar characteristics and contexts included in the present study. Moreover, the intervention was implemented at the whole class level; thus, future studies could deliver the instruction with small groups within the whole class. This would allow the researcher to study the data at both the group and individual level. Additionally, this study involved examining overall group results; hence, it is suggested that future studies should attend to individual scores in order to ensure improvement of writing performance among all students.

The present study examined the effect of the SRSD intervention on students' writing performance by examining pre-test and post-test phases only without any follow up maintenance. This limitation can be attributed to the amount of time available at schools; it was not feasible to schools to offer the researcher more than 10-12 weeks to conduct the experiment and attend classes. Due to this limited instructional time maintenance phase was not considered. Thus, future research should investigate the maintenance of the improvement on students' persuasive writing resulting from SRSD strategies.

Results revealed significant change in persuasive writing quality of the experimental group after the SRSD intervention. Writing quality as an outcome was analyzed in the present study using holistic rubric that yields a single score for general overall quality; thus, it is recommended that future studies use analytic scale to measure separate aspects of writing including content, vocabulary, organization, mechanics, and other writing areas. Likewise, this present study examined the effectiveness of the SRSD model on writing performance including elements of opinion essay, linking words, number of words, and writing quality. Further research should examine the effect of the SRSD intervention on building students' vocabulary due to its importance in developing students' writing skills (Graham \& Perin, 2007b).

\subsection{Final Thought}

As a final thought, there is a need to identify effective evidence-based writing practices (Fidalgo et al., 2017) to meet the globally shared concerns of difficulties associated in writing acquisition (Graham, 2019). Accordingly, the applicability of SRSD as a writing model across different cultures and its effectiveness in improving students writing performance (Robledo-Ramón \& García, 2017) guided the present study to examine the effect of the SRSD writing model on Grade 6 students' writing performance in the Lebanese context. The significant effectiveness of the SRSD writing strategies in enhancing writing performance of Grade 6 students in the Lebanese context provides additional evidence on the generalizability of the SRSD model to different cultures.

Remarkably, the present study noted several trends that are recognized in writing research, one of which is the assumption that the same cognitive processes involved in writing are globally observed ((Robledo-Ramón \& García, 2017), which in turn supports the view that students acquire second language writing through similar ways used by first language writers (Cumming, 2016). Furthermore, extensive research has demonstrated the applicability and effectiveness of the SRSD writing model in improving writing performance across different grades, students, and cultures (Fidalgo et al., 2017). On the basis of these assumptions, the advancement of universal literacy might be considered as a promising trajectory for designing effective universal writing instructions; thus, future research in writing in different contexts should be stimulated in this direction. Finally, results from the present study can be considered a contribution along this path.

\section{References}

Andrews, R., Torgerson, C., Low, G., \& McGuinn, N. (2009). Teaching argument writing to 7 - to 14 - year olds: an international review of the evidence of successful practice. Cambridge Journal of Education, 39(3), 291-310. https://doi.org/10.1080/03057640903103751

Awada, G., \& Diab, H. (2016). Lebanon's 2011 ICT education reform strategy and action plan: Curriculum success $\begin{array}{lllll}\text { or } & \text { Cogeyance. } & \text { Education, } & 3(1), & 1245086 .\end{array}$ https://www.tandfonline.com/doi/full/10.1080/2331186X.2016.1245086

Bandura, A. (1986). Social foundations of thought and action: A social cognitive theory. Englewood Cliffs, NJ: Prentice Hall Barkel, 2018).

Barkel, A. A. (2018). Self-regulated strategy development writing instruction with elementary aged students learning English. (Published dissertation, Arizona State University). https://repository.asu.edu/attachments/207563/content/Barkel_asu_0010E_18182

Brown, A. L., Campione, J. C., \& Day, J. D. (1981). Learning to learn: On training students to learn from texts. Educational Researcher, 10(2), 14-21. https://doi.org/10.2307/1174401

Bruning, R., \& Kauffman, D. F. (2016). Self-efficacy beliefs and motivation in writing development. In C. A. MacArthur, S. Graham, \& J. Fitzgerald (Eds.), Handbook of writing research (2nd Ed., pp. 160-173). New York, NY: Guilford Press.

Cuenca-Carlino, Y., Gozur, M., Jozwik, S., \& Krissinger, E. (2018). The impact of self-regulated strategy development on the writing performance of English learners. Reading \& Writing Quarterly, 34(3), $248-262$. 
https://doi.org/10.1080/10573569.2017.1407977

Cumming, A. (2016). Writing development and instruction for English language learners. In C. A. MacArthur, S. Graham, \& J. Fitzgerald (Eds.), Handbook of writing research (2nd Ed., pp. 364-376). New York, NY: Guilford Press.

Daouk, S. (2009). Self-regulated learning in second language classrooms. (Unpublished thesis, Lebanese American University). https://doi.org/10.26756/th.2009.12

De la Paz, S., \& Graham, S. (2002). Explicitly teaching strategies, skills, and knowledge: Writing instruction in middle school classrooms. Journal of Educational Psychology, 94(4), 687. https://doi.org/10.1037/00220663.94.4.687

De la Paz, S., \& Sherman, C. K. (2013). Revising strategy instruction in inclusive settings: Effects for English learners and novice writers. Learning Disabilities Research and Practice, 28, 129-141. https://doi.org/10.1111/ldrp.12011

Esseili, F. (2014). English language teaching in Lebanon: Trends and challenges. In K. M. Bailey \& R. M. Damerow (Eds.), The teaching and learning of English in the Arabic speaking world (pp. 101-114). New York: Routledge. https://doi.org/10.4324/9781315818856-15

Esseili, F. (2019) Innovation in writing instruction: Towards nurturing confident, motivated and academically honest L2 writers. In H., Reinders, C. Coombe, A. Littlejohn, \& D. Tafazoli (Eds.), Innovation in language learning and teaching. London: Palgrave Macmillan

Festas, I., Oliveira, A. L., Rebelo, J. A., Damião, M. H., Harris, K., \& Graham, S. (2015). Professional development in self-regulated strategy development: Effects on the writing performance of eighth grade Portuguese students. Contemporary Educational Psychology, 40, 17-27. https://doi.org/10.1016/j.cedpsych.2014.05.004

Fidalgo, R., \&Torrance, M. (2017). Developing writing skills through cognitive self-regulation instruction. In R. Fidalgo \& T. Olive (Series Eds.) \& R. Fidalgo, K. R. Harris, \& M. Braaksma (Vol. Eds.), Studies in Writing Series: Vol. 34. Design Principles for Teaching Effective Writing (pp. 89-118). Leiden: Brill.

Fidalgo, R., Harris, K. R., \& Braaksma, M. (2017). Design Principles for Teaching Effective Writing: An Introduction. In R. Fidalgo \& T. Olive (Series Eds.) \& R. Fidalgo, K. R. Harris, \& M. Braaksma(Vol. Eds.), Studies in Writing Series: Vol. 34. Design Principles for Teaching Effective Writing (pp. 3-12). Leiden: Brill.

Finlayson, K., \& McCrudden, M. T. (2020). Teacher-implemented writing instruction for elementary students: A literature review. Reading \& Writing Quarterly, 36(1), https://doi.org/10.1080/10573569.2019.1604278

Graham, S. (2018). A revised writer(s)-within-community model of writing. Educational Psychologist, 53(4), 258279. https://doi.org/10.1080/00461520.2018.1481406

Graham, S. (2019). Changing how writing is taught. Review of Research in Education, 43(1), $277-303$. https://doi.org/10.3102/0091732X18821125

Graham, S., \& Harris, K. R. (2017). Evidence-based writing practices: A meta-analysis of existing meta-analyses. In R. Fidalgo \& T. Olive (Series Eds.) \& R. Fidalgo, K. R. Harris, \& M. Braaksma (Vol. Eds.) Studies in Writing Series: Vol. 34. Design Principles for Teaching Effective Writing (pp. 13-37). Leiden: Brill.

Graham, S., \& Harris, K.R. (2014). Conducting high quality writing intervention research: Twelve recommendations. Journal of Writing Research, 6, 89-123. https://doi.org./10.17239/jowr-2014.06.02.1

Graham, S., \& Harris, K.R. (2019). Designing an effective writing program. In S. Graham, C. MacArthur, \& M. Hebert (Eds.), Best practices in writing instruction (3rd Edition, pp. 3-28). NY: Guilford.

Graham, S., \& Perin, D. (2007a). A meta-analysis of writing instruction for adolescent students. Journal of Educational Psychology, 99(3), 445-476. https://doi.org/10.1037/0022-0663.99.3.445

Graham, S., \& Perin, D. (2007b). Writing next: Effective strategies to improve writing of adolescents in middle and high schools A report to Carnegie Corporation of New York.Washington, DC: Alliance for Excellent Education.

Graham, S., Gillespie, A., McKeown, D. (2013). Writing: Importance, development, and instruction. Reading and Writing, 26(1), 1-15. https://doi.org/10.1007/s11145-012-9395-2

Graham, S., Harris, K. R., \& Mason, L. H. (2005). Improving the writing performance, knowledge, and selfefficacy of struggling young writers: The effects of self-regulated strategy development. Contemporary Educational Psychology, 30, 207-241. http://doi.org/10.1016/j.cedpsych.2004.08.001

Graham, S., Harris, K. R., \& Santangelo, T. (2015). Research-based writing practices and the common core: Metaanalysis and meta-synthesis. The Elementary School Journal, 115(4), $498 \quad 522$. https://doi.org/10.1086/681964

Graham, S., McKeown, D., Kiuhara, S., \& Harris, K. R. (2012). A meta-analysis of writing instruction for students in the elementary grades. Journal of Educational Psychology, 104(4), 879-896. https://doi.org/10.1037/a0029185

Harris, K. R., \& Graham, S. (2009). Self-regulated strategy development in writing: Premises, evolution, and the future. British Journal of Educational Psychology, 2(6), 113-135. 
https://doi.org/10.1348/978185409X422542

Harris, K. R., \& Graham, S. (2017). Self-regulated strategy development: Theoretical bases, critical instructional elements, and future research. In R. Fidalgo \& T. Olive (Series Eds.) \& R. Fidalgo, K. R. Harris, \& M. Braaksma (Vol. Eds.) Studies in Writing Series: Vol. 34. Design Principles for Teaching Effective Writing (pp. 119-151). Leiden: Brill. https://doi.org/10.1163/9789004270480 007

Harris, K. R., Graham, S., \& Adkins, M. (2015). Practice-based professional development and self-regulated strategy development for tier 2, at-risk writers in second grade. Contemporary Educational Psychology, 40, 5-16. https://doi.org/10.1016/j.cedpsych.2014.02.003

Harris, K. R., Graham, S., \& Mason, L. (2006). Improving the writing, knowledge, and motivation of young struggling writers: Effects of self-regulated strategy development with and without peer support. American Educational Research Journal, 43, 295-340. https://doi.org/10.3102/00028312043002295.

Harris, K. R., Graham, S., Brindle, M., \& Sandmel, K. (2009). Metacognition and children's writing. In D. Hacker, J. Dunlosky, \& A. Graesser (Eds.), Handbook of metacognition in education (pp.131-153). Mahwah, NJ: Erlbaum.

Harris, K. R., Graham, S., MacArthur, C., Reid, R., \& Mason, L. H. (2011). Self-regulated learning processes and children's writing. In B. J. Zimmerman \& D. H. Schunk (Eds.), Handbook of self-regulation of learning and performance (pp.187-202). New York, NY: Routledg.

Harris, K. R., Lane, K. L., Driscoll, S. A., Graham, S., Wilson, K., Sandmel, K., . . Schatschneider, C. (2012). Tier 1, teacher-implemented self-regulated strategy development for students with and without behavioral challenges: A randomized controlled trial. The Elementary School Journal, 113(2), 160-191. https://doi.org/10.1086/667403

Harris, K. R., Ray, A., Graham, S., \& Houston, J. (2019). Answering the challenge: SRSD instruction for close reading of text to write to persuade with 4 th and 5 th grade students experiencing writing difficulties. Reading and Writing, 32(6), 1459-1482. https://doi.org/10.1007/s11145-018-9910-1

Hayes, J. R. (1996). A new framework for understanding cognition and affect in writing. In C. M. Levy \& S. Ransdell (Eds.), The Science of Writing: Theories, methods, individual differences, and applications (pp. 127). Mahwah, NJ: Erlbaum.

Hayes, J. R. (2006). New directions in writing theory. In C. A. MacArthur, S. Graham, \& J. Fitzgerald (Eds.), Handbook of writing research (p. 28-40). The Guilford Press.

Hayes, J. R., \& Flower, L. (1980). Identifying the organization of writing processes. In L. W. Gregg \& E. R. Steinberg (Eds.), Cognitive processes in writing (pp. 3-30). Hillsdale, NJ: Erlbaum.

Hodges, T. (2017) Theoretically Speaking: An Examination of Four Theories and How They Support Writing in the Classroom, The Clearing House: A Journal of Educational Strategies, Issues and Ideas, 90:4, 139-146. https://doi.org/10.1080/00098655.2017.1326228

Itani, R. S., (1996). Motivational beliefs and self-regulated learning strategies as predictors of academic achievement in secondary schools in Beirut. (Unpublished Masters' thesis). American University of Beirut. Lebanon. http://hdl.handle.net/10938/5115

Limpo, T., \& Alves, R. A. (2013). Teaching planning or sentence-combining strategies: Effective SRSD interventions at different levels of written composition. Contemporary Educational Psychology, 38(4), 328. https://doi.org/10.1016/j.cedpsych.2013.07.004

MacArthur, C. A. (2017). Thoughts on What Makes Strategy Instruction Work and How It Can Be Enhanced and Extended. In R. Fidalgo \& T. Olive (Series Eds.) \& R. Fidalgo, K. R. Harris, \& M. Braaksma (Vol. Eds.), Studies in Writing Series: Vol. 34. Design Principles for Teaching Effective Writing (pp. 235-252). Leiden: Brill.

MacArthur, C. A., \& Graham, S. (2016). Writing research from a cognitive perspective. In C. A. MacArthur, S. Graham, \& J. Fitzgerald (Eds.), Handbook of writing research (2nd Ed., pp. 24-40). New York, NY: Guilford Press.

McKeown, D., FitzPatrick, E., Brown, M., Brindle, M., Owens, J., \& Hendrick, R. (2019). Urban teachers' implementation of SRSD for persuasive writing following practice-based professional development: Positive effects mediated by compromised fidelity. Reading and Writing, 32(6), 1483-1506. https://doi.org/10.1007/s11145-018-9864-3

Meichenbaum, D. (1977). Cognitive behavior modification: An integrative approach. New York, NY: Plenum.

Robledo-Ramón, P., \& García, J. N. (2017). Description and analysis of strategy-focused iInstructional models for writing. In R. Fidalgo \&T. Olive (Series Eds.) \& R. Fidalgo, K. R. Harris, \& M. Braaksma (Vol. Eds.), Studies in Writing Series: Vol. 34. Design Principles for Teaching Effective Writing (pp. 38-65). Leiden: Brill.

Rubeiz, I. E., (1995). The relationship between self-regulation and academic achievement in Lebanese private elementary school students. (Unpublished Master's thesis), American University of Beirut, Lebanon. https://ulib.aub.edu.lb/thesis/t-3644.pdf

Scardamalia, M., \& Bereiter, C. (1986). Written composition. In M. Wittrock (Ed.), Handbook of research on 
teaching (3rd Ed., pp. 778-803). New York: MacMillan.

Shaaban, K. A. (2013). Disparity between ideals and reality in curriculum construction: The case of the Lebanese English language curriculum. Creative Education, 4(12), 28. https://doi.org/10.4236/ce.2013.412A2005

Smith, S. W., Daunic, A. P., \& Taylor, G. G. (2007). Treatment fidelity in applied educational research: Expanding the adoption and application of measures to ensure evidence-based practice. Education and treatment of children, 30(4), 121-134. https://doi.org/10.1353/etc.2007.0033

Vygotsky, L. (1986). Thought and language. Cambridge, MA: MIT Press.

Vygotsky, L. S. (1978). Mind in society: The development of higher psychological processes. Cambridge: Harvard University Press.

Witt, J. C., \& Elliott, S. N. (1985). Acceptability of classroom intervention strategies. In T. R. Kratochwill (Ed.), Advances in school psychology (Vol. 4., pp. 251-288). Mahwah, NJ: Erlbaum.

Wolters, C. A., Pintrich, P. R., \& Karabenick, S. A. (2003). Assessing self-regulated learning. Paper presented at the Conference on Indicators of Positive Development: Definitions, Measures, and Prospective Validity, March 12-13, 2003. https:/www.childtrends.org/wp-content/uploads/2013/05/Child_Trends2003_03_12_PD_PDConfWPK.pdf

Zimmerman, B. J., \& Risemberg, R. (1997). Becoming a self-regulated writer: A social cognitive perspective. Contemporary Educational Psychology, 22, 73-101. https://doi.org/10.1006/ceps.1997.091

\begin{abstract}
About Authors
Najla Mazeh, is an instructor at the Lebanese University/faculty of Public Health since 2008. She teaches courses related to the field of cognitive psychology, theories of intelligence, special education and educational assessment. She is the founder and director of a private center, devoted to educational measurement $\&$ intervention of students with learning difficulties. She received her Teaching Diploma in special education in 1998 and her Master's degree in educational psychology with emphasis on test and measurement in 2007 from the American University of Beirut. Her specialization is in cognition, learning, assessment and development. She fulfilled the requirements of the $\mathrm{PhD}$ program at Saint-Joseph University of Beirut.

Dr. Nehme Safa is an associate professor at Saint Joseph University of Beirut, Faculty of Educational Sciences. $\mathrm{He}$ is responsible for carrying out research projects at the Educational Research Laboratory, Faculty of Educational Sciences. Dr. Safa teaches courses at the graduate level, and gives seminars at the post graduate level.
\end{abstract}

